\title{
Commentary
}

\section{Are Avoidance Goals the Right Prescription For a Pandemic? A COVID-19 Case Study}

\author{
Geoffrey V. Henderson ${ }^{1 *}$, Andrew J. Elliot ${ }^{2}$ \\ ${ }^{1}$ Syracuse DVAMC and SUNY Upstate Medical Center, 800 Irving Ave., Syracuse, NY 13210, USA. \\ ${ }^{2}$ University of Rochester, 488 Meliora Hall, Rochester, NY 14627, USA.
}

Received 19 July 2021; Revised 21 September 2021; Accepted 08 October 2021; Published 01 December 2021

\begin{abstract}
Background: Motivation scientists study goals, self-regulatory tools that are used to help people approach or avoid objects of desire or disdain. Purpose: Using these tools, motivation science can offer insights to guide behaviour and help individuals maintain optimal health and well-being during pandemics, including COVID-19. Results: Avoidance goals help guide behaviour away from negative objects like COVID-19, and are necessary in situations where survival is at stake. Formulating the goal of avoiding COVID-19 is therefore recommended during the pandemic. However, avoidance goals have inherent limitations, in that they tax one's energy and well-being. To minimize these costs, the pursuit of approach sub-goals may be recommended, such as increasing social connection online or exercising outdoors (particularly prior to widespread vaccination). Conclusion: Adhering to the goal of avoiding COVID-19 prevents infection and saves lives when safe and effective vaccines and treatments are lacking. But avoidance goals have known costs that must be acknowledged and addressed. One solution is to pair avoidance goals with approach sub-goals to bolster mental and physical health while adhering to the ultimate goal of avoiding COVID-19, viral variants, and future contagions.
\end{abstract}

Keywords: Approach-Avoidance Motivation; Goals; Hierarchical Model; COVID-19.

\section{Introduction}

A new zoonotic disease emerged at the close of 2019, caused by the novel coronavirus SARS-CoV-2 [1]. The virus spread rapidly and rampantly, and by mid-March 2020, this disease - COVID-19 - had been declared a global pandemic [2]. Initially hampered by a paucity of pharmaceutical options like vaccines or effective treatments, individuals struggled to find the best prescription to maintain health. We look back on the early response to COVID19 from the perspective of motivation science, and offer some suggestions for future outbreaks (or, in countries where vaccination is sparse, suggestions for the present).

\section{A time for Avoidance?}

To understand this phenomenon, we must first understand the central issue: COVID-19 is a disease; it is aberrant to normal, human physiology. Therefore, the COVID-19 pandemic, at its core, is a health-related issue. True, the pandemic has engendered myriad downstream effects - on a macro level, jolting world economies and political institutions, and on a micro level, affecting plans and protocols regarding school closings and public gatherings. The

* Corresponding author: geoffrey.henderson@va.gov

doi http://dx.doi.org/10.28991/SciMedJ-2021-0304-7

> This is an open access article under the CC-BY license (https://creativecommons.org/licenses/by/4.0/).

(C) Authors retain all copyrights. 
scope of these issues belies the fact that at the heart of the pandemic is a simple, straightforward assessment: health and lives are at stake.

Second, the pandemic is a decidedly negative event: it threatens the health and safety of countless millions. In its best light, COVID-19 could be viewed (by some) as health neutral, dismissed as akin to the common cold. Former President Donald Trump, after his bout with the virus, tweeted: “Don't be afraid of Covid. Don't let it dominate your life" [3]. More consistent with the data (in our estimation), SARS-CoV-2 is a deadly virus, especially for those who are older and have certain co-morbidities [4], and has killed nearly five million people worldwide [5].

In light of this threat, how should one respond? What goals should one pursue? Here, motivation science offers guidance. Goals have been studied from ancient to modern times, informed by philosophical insights and scientific inquiries, and a few key concepts have emerged. Goals are consciously chosen (which distinguishes them from unconscious urges or propensities). Goals are forms of regulation that guide behaviour (which distinguishes them from wants and wishes). And, goals guide behaviour toward or away from objects (a term used broadly to capture objects, events, or possibilities) [6]. Some objects are positive and are pursued (approached), whereas other objects are negative and are shunned (avoided). The commitment to approach positive objects (move toward them) and avoid negative objects (move away from them) is a fundamental property of goals and goal pursuit [7]. This approachavoidance dichotomy offers a useful lens to examine responses to the pandemic.

Notably, approach goals are generally preferred to avoidance goals with respect to guiding behaviour and fostering well-being. Structurally, an approach goal focuses on a positive possibility and offers precise direction - moving toward a desired object. Thus, successful goal pursuit results in achieving a desired (and previously absent) end-state. Successful pursuit also yields positive emotions and well-being - the plaudits of success [8]. Not achieving an approach goal may leave the pursuer worse off temporarily, but the current absence of the desired state is thought to be a neutral launching pad toward further efforts [9].

Given the benefits of approach goals, one wonders if they would be ideal for navigating a pandemic like COVID19. While the advantages of approach goals are well-documented, avoidance goals nonetheless seem a better fit, as the hub of regulation is decidedly negative (COVI9-19 is a negative object, and the pandemic a negative event). In other words, it makes sense to use avoidance goals during a pandemic to guide behaviour and avoid disease. An approach goal focused on the disease itself is incongruent, as there is no positive object to move toward. We find no support for the adage: "What doesn't kill you makes you stronger." There are no touted benefits of infection, as far as we are aware, no physiologic improvements after infection that would qualify as a plus, with the possible exception of developing antibodies that help prevent future infection (though even in this case, the benefit is avoiding another negative). Approach motivation is about thriving; avoidance motivation is about surviving [10]. In a health crisis, surviving is the crucial end-state; in these circumstances, avoidance goals seem the best fit.

In practice, avoidance goals have already been implemented on macro (global) and micro (personal) scales. Prior to vaccines, avoiding COVID-19 centred around behavioural interventions like banning travel; closing schools, businesses, and places of worship; disbanding large gatherings; quarantining disease carriers and suspected disease carriers; issuing stay at home orders; and encouraging social distancing [11]. Is there evidence to suggest that these avoidance-based interventions - designed to avoid person-to-person viral spread - are effective? In a word, yes. To cite a few examples:

- In China, "[e]arly detection and isolation of cases prevented more infections than did travel restrictions and contact reductions, but ... a combination of [behavioural interventions] achieved the strongest and most rapid effect" [12].

- In a study of 11 European countries, researchers found that behavioural interventions, particularly lockdowns, significantly reduced transmission and prevented 3.1 (2.8 - 3.5) million deaths [13].

- The combined effect of behavioural interventions - such as school closures and restricting people to homes - in areas of China, South Korea, Italy, Iran, France, and the United States reduced transmission rates and prevented or delayed approximately 61 million cases [11].

- In a study across 130 countries and territories, researchers determined that "the effectiveness of school closure and internal movement restrictions appears robust" in reducing COVID-19 transmission [14].

- Historically, during the 1918-1919 influenza pandemic, cities in the United States that implemented "early [and] sustained" behavioural interventions had lower mortality [15].

\section{Limitations of Avoidance Goals, and a Solution}

Thus, with respect to COVID-19, avoidance behaviour works. Avoidance goals promote vigilance and attention to detail, prime the body to anticipate and react to threats, and evoke careful, restrictive action [16]. These processes have 
helped people stay safe during the pandemic. However, the regulation of avoidance behaviour is a double-edged sword. Avoidance behaviour saps energy, undermines well-being, and under-cuts performance over time [17]. Avoidance regulation focuses on a negative object, and can evoke fear and anxiety. This heightened state can help one navigate threats (like navigating icy highways in winter, when avoiding a car accident helps drivers arrive safely at their destination; or, in the case of COVID-19, in avoiding deadly microbes). But this mindset exacts a cost, and can feel "urgent and all-consuming" [16]. It is little surprise that air traffic controllers - whose job description focuses inherently on avoidance - ensuring planes evade mid-air collisions - suffer from a high rate of burn-out [18]. It is also little surprise that individuals in the pandemic have had worsening anxiety and mental health. In mid-March 2020, with the declaration of a national emergency in the United States, internet searches regarding acute anxiety spiked compared to historical levels [19]. A study conducted in late March and early April found depression symptoms had jumped more than three-fold in the U.S. [20]. A U.S. Census Bureau study echoed these results. Compared to a sample in 2019 (pre-pandemic), the prevalence of anxiety and depression climbed three times higher during the pandemic [21]. Spikes in mental health disorders have extended beyond the United States as well. A systematic review reported increased rates of anxiety and depression as a result of COVID-19 - in addition to stress and post-traumatic stress disorder - in the general populations of China, Spain, Italy, Iran, the US, Turkey, Nepal, and Denmark [22].

Avoidance goals have inherent limitations, as revealed by their structure. Given that the hub of regulation is a negative object, the best outcome is successfully avoiding that negative object and, hence, the best emotional outcome is relief [23]. Given that avoidance regulation is directed away from an object, an unanswered question remains: toward what object should one move? This type of regulation offers little guidance [9]. That does not mean avoidance behaviour should be eschewed; it means instead that the utility of avoidance behaviour may be limited to situations that represent dire threats to health and safety. Avoidance goals seem to be the right tool for times when danger is imminent and survival uncertain, when it is prudent to be on high alert. Survive today in order to thrive tomorrow, when danger has dissipated and safety is assured.

But if the costs of avoidance goals are so burdensome, are there ways to offset these costs? Motivation science answers in the affirmative. Avoidance and approach goals can exist in a hierarchical model, with a superordinate goal coupled with sub-goals [24]. Avoiding COVID-19 may be the superordinate goal, the unifying framework that guides behaviour, but sub-goals are possible that are not avoidant in nature. For example, prior to widespread vaccination, avoiding COVID-19 may have one practicing social isolation; to counterbalance this loneliness, an approach goal could be considered to promote healthy relationships (a positive object) through online interactions (via Zoom or FaceTime). Avoiding COVID-19 may prompt the avoidance of gyms; an approach goal to offset this loss may be to exercise and maintain a healthy body (a positive object) by walking or jogging outside, or riding a stationary bike inside. People have noted pandemic "fatigue" and burn-out; approach sub-goals may help to "replenish and reinvigorate" [16]. Approach goals - like those above - can help guide behaviour even as the as the crux of behaviour falls under the auspices of avoidance.

\section{Conclusion}

At its core, COVID-19 is a disease. At its worst, it represents a deadly assault to human health and physiology. The pandemic is a negative event - a threat to millions. During this and future pandemics, motivation scientists can offer insights to guide behaviour through their work on goals (regulatory tools in which people approach or avoid objects of desire or disdain). Avoidance goals are uniquely structured to help guide behaviour away from a negative object, and are necessary in situations where survival is at stake. Thus, formulating the goal of avoiding COVID-19 is recommended during the pandemic. Data suggests that adhering to this avoidance goal - at the societal and individual level - prevents infection and saves lives, particularly prior to widespread vaccination. But like any medical prescription, adherence entails risks and benefits. Avoidance goals come at a steep cost to energy, well-being, and long-term performance. To minimize these known "side-effects," a hierarchical model of goal pursuit is recommended: adding approach sub-goals to bolster mental and physical health while adhering to the ultimate superordinate goal of avoiding COVID-19, viral variants, and future contagions.

\section{Declarations}

\subsection{Author Contributions}

Conceptualization, G.H. and A.E.; methodology, G.H. and A.E.; investigation, G.H. and A.E.; resources, G.H. and A.E.; data curation, G.H. and A.E.; writing — original draft preparation, G.H.; writing — review and editing, G.H. and A.E.; supervision, A.E. All authors have read and agreed to the published version of the manuscript.

\subsection{Funding}

The authors received no financial support for the research, authorship, and/or publication of this article. 


\subsection{Ethical Approval}

Not applicable.

\subsection{Data Availability Statement}

Data sharing is not applicable to this article.

\subsection{Conflict of Interest}

The authors declare that they have no known competing financial interests or personal relationships that could have appeared to influence the work reported in this paper.

\section{References}

[1] World Health Organization, WHO. (2020, September 9) Timeline of WHO's response to COVID-19. Available online: https://www.who.int/news/item/29-06-2020-covidtimeline (accessed on 30 November 2020).

[2] World Health Organization WHO. (2020, March 11). WHO Director-General's opening remarks at the media briefing on COVID-19 - 11 March 2020. Available online: https://www.who.int/director-general/speeches/detail/who-director-general-sopening-remarks-at-the-media-briefing-on-covid-19---11-march-2020 (accessed on 01 December 2020).

[3] Trump, D. (2020, October 5). I will be leaving the great Walter Reed Medical Center today at 6:30 P.M. Available online: https://twitter.com/realdonaldtrump/status/1313186529058136070?lang=en (accessed on 30 November 2020).

[4] Williamson, E. J., Walker, A. J., Bhaskaran, K., Bacon, S., Bates, C., Morton, C. E., Curtis, H. J., Mehrkar, A., Evans, D., Inglesby, P., Cockburn, J., McDonald, H. I., MacKenna, B., Tomlinson, L., Douglas, I. J., Rentsch, C. T., Mathur, R., Wong, A. Y. S., Grieve, R., Harrison, D., Forbes, H., Schultze, A., Croker, R., Parry, J., Hester, F., Harper, S., Perera, R., Evans, S. J. W., Smeeth, L., Goldacre, B. (2020). Factors associated with COVID-19-related death using OpenSAFELY. Nature, 584(7821), 430-436. doi:10.1038/s41586-020-2521-4.

[5] World Health Organization, WHO. (2020) COVID-19 Dashboard. Geneva: World Health Organization, Available online: https://covid19. who.int. (accessed on 21 October 2021).

[6] Elliot, A. J., \& Fryer, J. W. (2008). The goal construct in psychology. In J. Shah \& W. Gardner (Eds.). Handbook of motivation science (18), 235-250. New York: The Guilford Press.

[7] Elliot, A. J., \& Covington, M. V. (2001). Approach and avoidance motivation. Educational Psychology Review, (13), 73-92.

[8] Elliot, A. J., \& Friedman, R. (2007). Approach and avoidance personal goals. In B. Little, K. Salmela-Aro, \& S. Phillips (Eds.), Personal project pursuit: Goals, action, and human flourishing, 97-116. Hillsdale, NJ: Lawrence Erlbaum Associates.

[9] Carver, C. S., \& Scheier, M. F. (1998). On the Self-Regulation of Behavior. Cambridge: Cambridge University Press. doi:CBO9781139174794.

[10] Elliot, A. J., \& Gable, S. L. (2019). Functions and Hierarchical Combinations of Approach and Avoidance Motivation. Psychological Inquiry, 30(3), 130-131. doi:10.1080/1047840x.2019.1646042.

[11] Hsiang, S., Allen, D., Annan-Phan, S., Bell, K., Bolliger, I., Chong, T., Druckenmiller, H., Huang, L. Y., Hultgren, A., Krasovich, E., Lau, P., Lee, J., Rolf, E., Tseng, J., Wu, T. (2020). The effect of large-scale anti-contagion policies on the COVID-19 pandemic. Nature, 584(7820), 262-267. doi:10.1038/s41586-020-2404-8.

[12] Lai, S., Ruktanonchai, N. W., Zhou, L., Prosper, O., Luo, W., Floyd, J. R., Wesolowski, A., Santillana, M., Zhang, C., Du, X., Yu, H., Tatem, A. J. (2020). Effect of non-pharmaceutical interventions to contain COVID-19 in China. Nature, 585(7825), 410-413. doi:10.1038/s41586-020-2293-x.

[13] Flaxman, S., Mishra, S., Gandy, A., Unwin, H. J. T., Mellan, T. A., Coupland, H., Whittaker, C., Zhu, H., Berah, T., Eaton, J. W., Monod, M.; Imperial College COVID-19 Response Team, Ghani, A. C., Donnelly, C. A., Riley, S., Vollmer, M. A. C., Ferguson, N. M., Okell, L. C., Bhatt, S. (2020). Estimating the effects of non-pharmaceutical interventions on COVID-19 in Europe. Nature, 584(7820), 257-261. doi:10.1038/s41586-020-2405-7.

[14] Liu, Y., Morgenstern, C., Kelly, J., Lowe, R., CMMID COVID-19 Working Group, \& Jit, M. (2021). The impact of nonpharmaceutical interventions on SARS-CoV-2 transmission across 130 countries and territories. BMC Med 19(40). doi:10.1186/s12916-020-01872-8.

[15] Markel, H., Lipman, H. B., Navarro, J. A., Sloan, A., Michalsen, J. R., Stern, A. M., \& Cetron, M. S. (2007). Nonpharmaceutical interventions implemented by US cities during the 1918-1919 influenza pandemic. The Journal of the American Medical Association, 298(6), 644-654. doi:10.1001/jama.298.6.644. 
[16] Roskes, M., Elliot, A. J., \& De Dreu, C. K. W. (2014). Why is avoidance motivation problematic, and what can be done about it? Current Directions in Psychological Science, 23(2), 133-138. doi:10.1177/0963721414524224.

[17] Oertig, D., Schüler, J., Schnelle, J., Brandstätter, V., Roskes, M., \& Elliot, A. J. (2013). Avoidance goal pursuit depletes selfregulatory resources. Journal of Personality, 81(4), 365-375. doi:10.1111/jopy.12019.

[18] Samra, R. (2018). Brief history of burnout. BMJ (Clinical Research Ed.), 363, k5268. doi:10.1136/bmj.k5268.

[19] Ayers, J. W., Leas, E. C., Johnson, D. C., Poliak, A., Althouse, B. M., Dredze, M., \& Nobles, A. L. (2020). Internet Searches for Acute Anxiety during the Early Stages of the COVID-19 Pandemic. JAMA Internal Medicine, 180(12), 1706 doi:10.1001/jamainternmed.2020.3305.

[20] Ettman, C. K., Abdalla, S. M., Cohen, G. H., Sampson, L., Vivier, P. M., \& Galea, S. (2020). Prevalence of Depression Symptoms in US Adults Before and During the COVID-19 Pandemic. JAMA Network Open, 3(9), e2019686. doi:10.1001/jamanetworkopen.2020.19686.

[21] Twenge, J. M., \& Joiner, T. E. (2020). U.S. Census Bureau - assessed prevalence of anxiety and depressive symptoms in 2019 and during the 2020 COVID - 19 pandemic. Depression and Anxiety, 37(10), 954 - 956. doi:10.1002/da.23077.

[22] Xiong, J., Lipsitz, O., Nasri, F., Lui, L. M. W., Gill, H., Phan, L., ... McIntyre, R. S. (2020). Impact of COVID-19 pandemic on mental health in the general population: A systematic review. Journal of Affective Disorders, $277,55-64$. doi:10.1016/j.jad.2020.08.001.

[23] Higgins, E. T. (2011). Beyond pleasure and pain: How motivation works. Oxford University Press. doi:10.1093/acprof:oso/9780199765829.001.0001.

[24] Elliot, A. J. (2006). The Hierarchical Model of Approach-Avoidance Motivation. Motivation and Emotion, 30(2), 111-116. doi:10.1007/s11031-006-9028-7. 